\title{
Identification of cellular proteome using two-dimensional difference gel electrophoresis in ST cells infected with transmissible gastroenteritis coronavirus
}

\author{
Xin Zhang ${ }^{1}$, Hong-Yan Shi ${ }^{1}$, Jian-Fei Chen ${ }^{1}$, Da Shi ${ }^{1}$, Hong-Wu Lang ${ }^{2}$, Zhong-Tian Wang ${ }^{2}$ and Li Feng ${ }^{1 *}$
}

\begin{abstract}
Background: Transmissible gastroenteritis coronavirus (TGEV) is an enteropathogenic coronavirus that causes diarrhea in pigs, which is correlated with high morbidity and mortality in suckling piglets. Information remains limited about the comparative protein expression of host cells in response to TGEV infection. In this study, cellular protein response to TGEV infection in swine testes (ST) cells was analyzed, using the proteomic method of two-dimensional difference gel electrophoresis (2D DIGE) coupled with MALDI-TOF-TOF/MS identification.

Results: 33 differentially expressed protein spots, of which 23 were up-regulated and 10 were down-regulated were identified. All the protein spots were successfully identified. The identified proteins were involved in the regulation of essential processes such as cellular structure and integrity, RNA processing, protein biosynthesis and modification, vesicle transport, signal transduction, and the mitochondrial pathway. Western blot analysis was used to validate the changes of alpha tubulin, keratin 19, and prohibitin during TGEV infection.

Conclusions: To our knowledge, we have performed the first analysis of the proteomic changes in host cell during TGEV infection. 17 altered cellular proteins that differentially expressed in TGEV infection were identified. The present study provides protein-related information that should be useful for understanding the host cell response to TGEV infection and the underlying mechanism of TGEV replication and pathogenicity.
\end{abstract}

Keywords: Proteome, ST cell, DIGE, TGEV

\section{Background}

Transmissible gastroenteritis virus (TGEV) is a member of the Coronaviridae family [1]. The infection of TGEV causes severe diarrhea in suckling piglets (about 2 weeks old) and its lethality approaches $100 \%$, which results in enormous economic loss in swine-producing areas in the world [2]. TGEV is an enveloped virus with a positivesense RNA genome of $28.5 \mathrm{~kb}$. About two-thirds of the TGEV genome encodes the replicase proteins (rep) at the $5^{\prime}$ end, and one-third of the genome encodes other viral genes at the $3^{\prime}$ end in an order of $5^{\prime}$-S-3a-3b-E-M-N-7-3'

\footnotetext{
* Correspondence: fl@hvri.ac.cn

'Division of Swine Infectious Diseases, State Key Laboratory of Veterinary Biotechnology, Harbin Veterinary Research Institute, Chinese Academy of Agricultural Sciences, No. 427 Maduan Street, Nangang District, Harbin 150001, China

Full list of author information is available at the end of the article
}

[3]. The genome of TGEV encodes four structural proteins: spike (S), membrane (M,), minor envelope $(\mathrm{E})$, and nucleocapsid $(\mathrm{N})$ proteins. The surface protein $\mathrm{S}$, a large type I transmembrane glycoprotein that forms peplomers, is responsible for cell receptor binding and membrane fusion [4]. The M protein spans the membrane and interacts with the $\mathrm{N}$ protein to form core of the virus during assembly $[5,6]$. The small $E$ protein, a transmembrane protein detected as a minor structural component, is essential for TGEV replication [7]. The $\mathrm{N}$ protein, an internal phosphoprotein [8], interacts with the TGEV genomic RNA to form viral nucleocapsid [5,9], and may disrupt host cell division [10]. To date, there is limited information about host cell responses to TGEV infection.

Proteomics analysis enables a more comprehensive characterization of virus-virus and virus-host interactions 
involved in infection and pathogenesis [11,12]. The development of proteomic approaches have greatly facilitated detection of proteins induced in virus infected cells. Among those techniques for differentially expressed protein spot analysis, two-dimensional difference gel electrophoresis (2D DIGE) is reproducible and sensitive [13]. 2D DIGE has greatly facilitated the comparison of two samples by removing gel-to-gel variability and by using dyes (CyDye) with a greater dynamic range than traditionally used silver or Coomassie stains [14]. Using 2D DIGE method followed by mass spectrometry (MS) identification, comparative proteomics of host cells have been investigated during virus infection, including human influenza A virus [15], human immunodeficiency virus type 1 (HIV-1) [16], hepatitis B virus [17], hepatitis $C$ virus (HCV) [18], Epstein-Barr virus (EBV) [19], and Dengue virus (DENV) [20], and porcine reproductive and respiratory syndrome (PRRSV) [21]. Proteomics method analyzing host cellular responses to TGEV infection can be used to identify important cellular factors involved in viral pathogenesis.

In present study, to determine protein profiles of swine testes (ST) cell line that expressed differentially after TGEV infection, fluorescent 2D DIGE coupled with a MALDITOF-TOF/MS identification proteomics approach was utilized. A total of 33 differentially expressed protein spots were identified, and those proteins of interest were confirmed by Western blot. This study can provide useful clues for better understanding of TGEV replication and pathogenesis.

\section{Results}

\section{Confirmation of TGEV propagation in ST cells}

To obtain a detailed comparison of differences in protein expression, the cellular proteins were extracted at $24 \mathrm{~h}$, $48 \mathrm{~h}$ and $72 \mathrm{~h}$ p.i. from the TGEV-infected and mockinfected ST cells and were identified by IFA and Western blot analysis using $\mathrm{mAb}$ to $\mathrm{N}$ protein of TGEV as primary antibody. IFA and Western blot analysis revealed that the ST cells infected with TGEV could be recognized with $\mathrm{mAb}$ to $\mathrm{N}$ protein of the TGEV at $24 \mathrm{~h}, 48 \mathrm{~h}$ and $72 \mathrm{~h}$ p.i. (Figure 1). To determine the host response of ST cells following TGEV infection, the cytophatic effect (CPE) was also observed at $24 \mathrm{~h}, 48 \mathrm{~h}$, and $72 \mathrm{~h}$ p.i. TGEV induced significant CPE at $48 \mathrm{~h}$ and $72 \mathrm{~h}$ p.i., characterized by rounding and detachment of the cells (Figure 1A). TGEV-

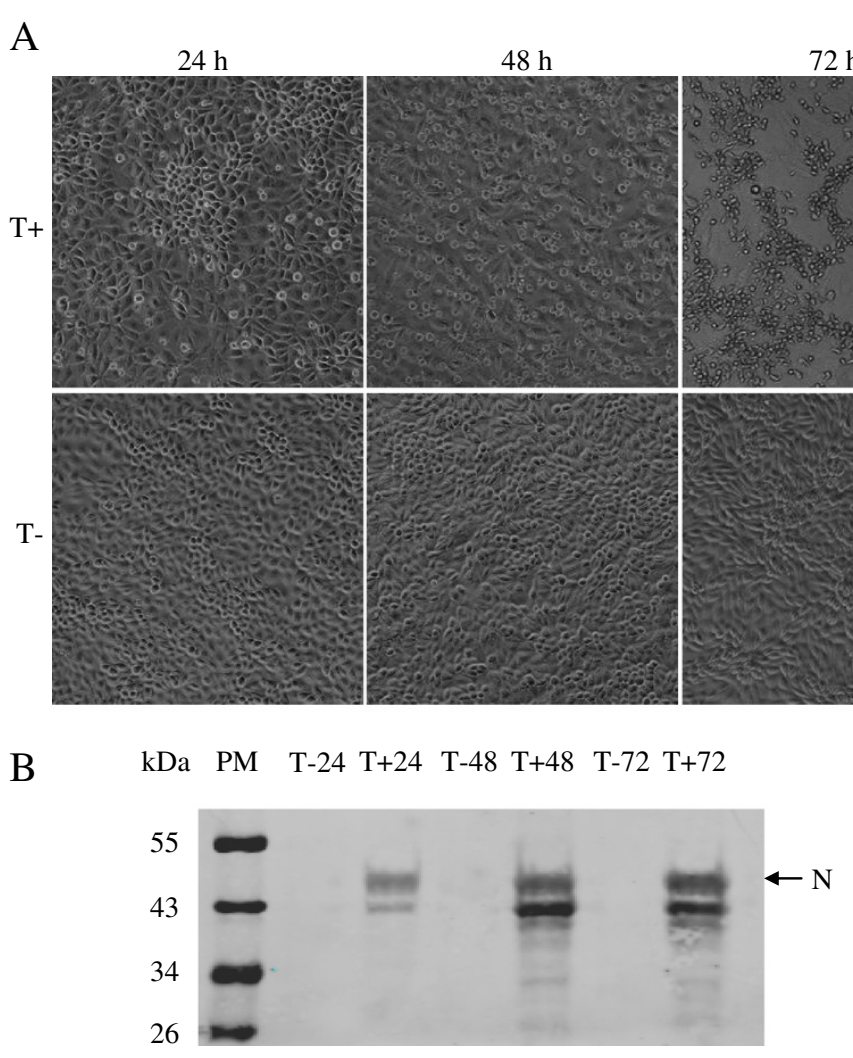

Figure 1 Cytopathic effect caused by TGEV infection and identification of the TGEV infected and non-infected ST cells. The cytophatic effect induced by the TGEV virus was analyzed by optical microscopy, at $24 \mathrm{~h}, 48 \mathrm{~h}$ and $72 \mathrm{~h}$ p.i. Images were taken with a 40X objective (A). The N protein in TGEV-infected and mock-infected ST cells were checked using the mAb to N protein of the TGEV by the method of Western blot (B). T + and T- represent the TGEV infected and uninfected ST cells, respectively. 
infected ST cells at $48 \mathrm{~h}$ p.i. were chosen for subsequent proteomics analysis, in which a high percentage of TGEVinfected cells showed considerable cell death.

\section{Analysis of differentially expressed proteins after TGEV infection}

To identify cell proteins involved in response to TGEV infection, 2D DIGE proteomics method was performed. Three independent experimental repeat of TGEVinfected and mock-infected ST cells were included in this analysis (Additional file 1: Figure S1). After 2D DIGE, the Cy2, Cy3, and Cy5 channels of each gel were individually imaged, and were analyzed using Decyder software package (version 6.04.11, GE Healthcare). For proteins separated in the $\mathrm{pH} 4-7$ range, 2,710 protein spots were matched. Of which, 33 spots were significantly modified between the TGEV-infected and mock-infected ST cells (2-fold difference in abundance and $p<0.05$ ), including 23 spots that were up-regulated and 10 that were down-regulated (Figure 2 and Figure 3).

\section{Mass spectral identification of differentially expressed proteins}

To identify the differentially expressed proteins in TGEVinfected ST cells, a total of 33 protein spots with a threshold greater than 2-fold were excised manually from gels and subjected to in-gel trypsin digestion and subsequent MALDI-TOF/TOF identification. As shown in Figure 4 and Table 1, 33 differentially expressed protein spots (Additional file 2: Table S1), comprising 23 up-regulated and 10 down-regulated protein spots, were successfully identified (the MS and MS/MS spectra are listed in

A

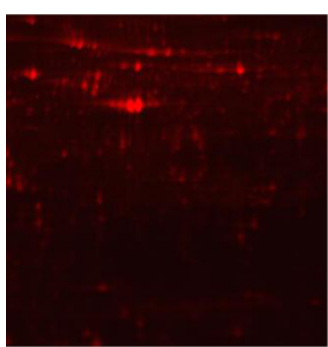

Cy3

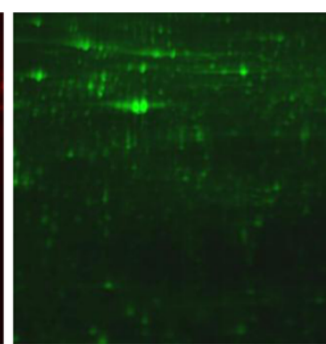

Cy5



Cy2

B
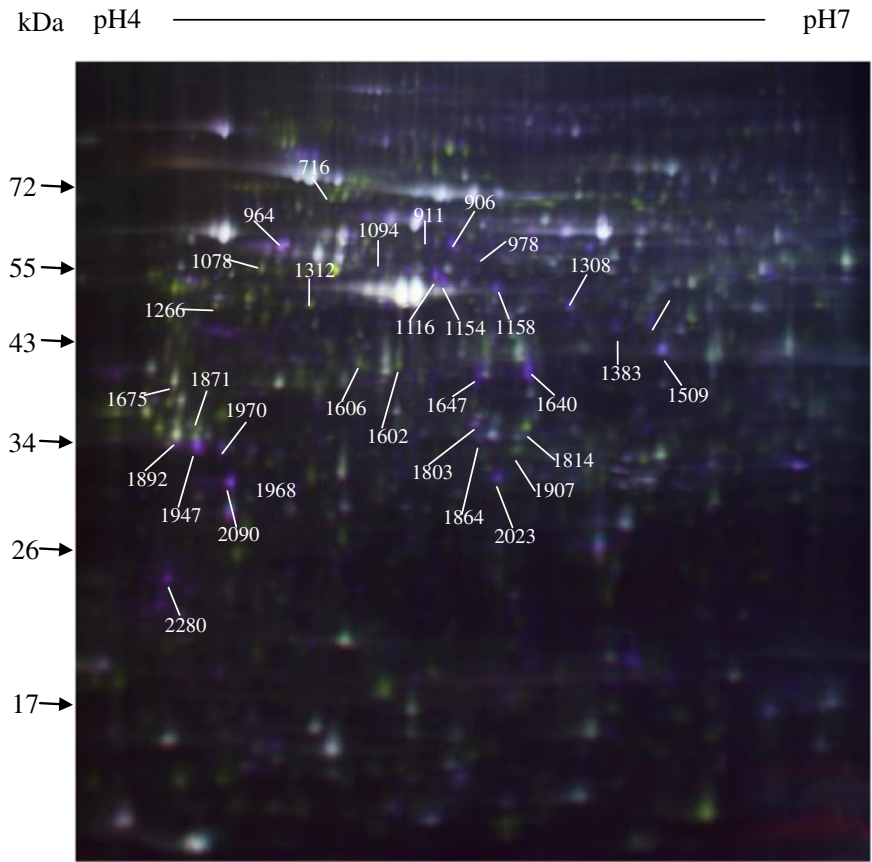

Figure 2 Differentially expressed protein spots (marker with master numbers) displayed in 2D DIGE images. The TGEV-infected ST cell lysates are labeled with Cy3 (red), the mock-infected ST cells are labeled with Cy5 (blue), the internal standard proteins are labeled with Cy2 (yellow) (A). Representative data from a 2D DIGE (B). 
Cytoskeleton proteins

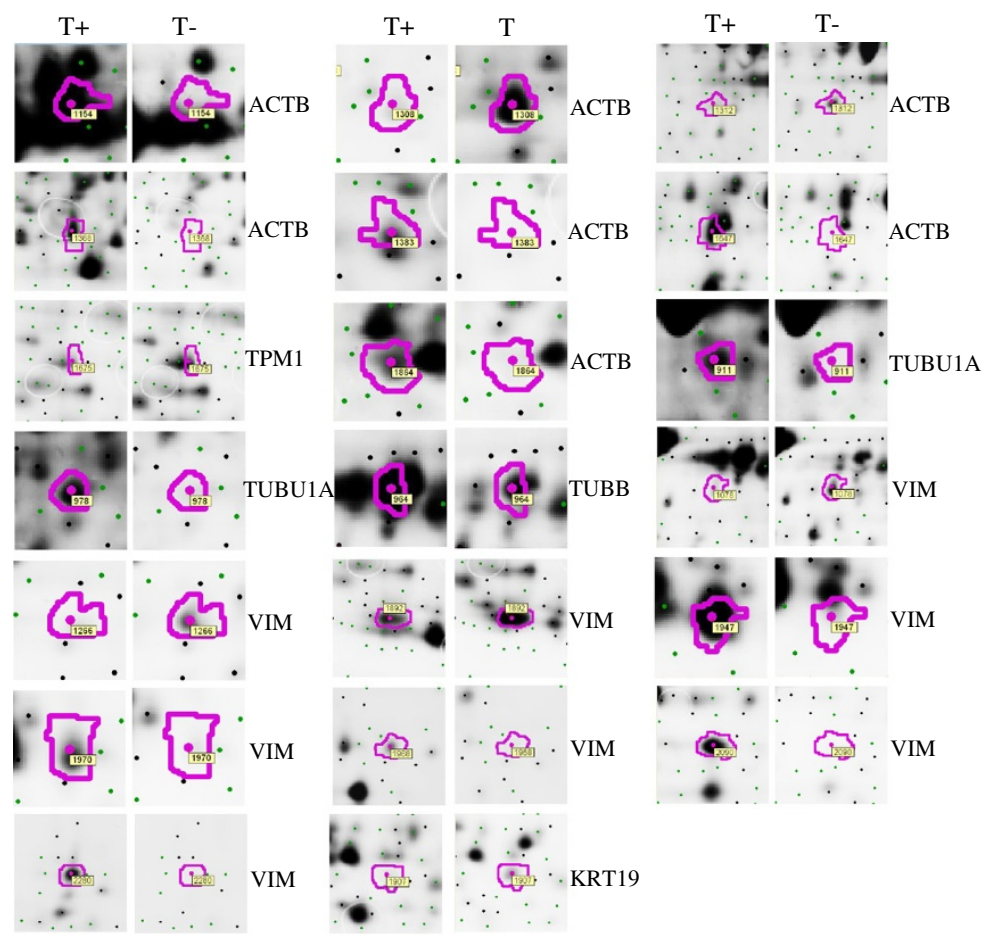

RNA processing

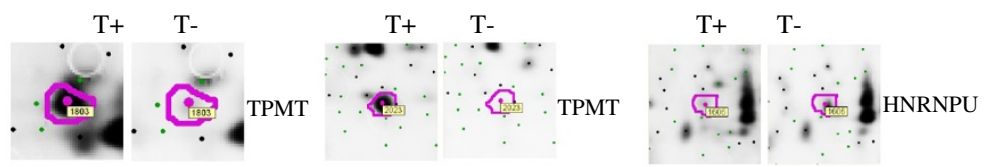

Protein biosynthesis and modification
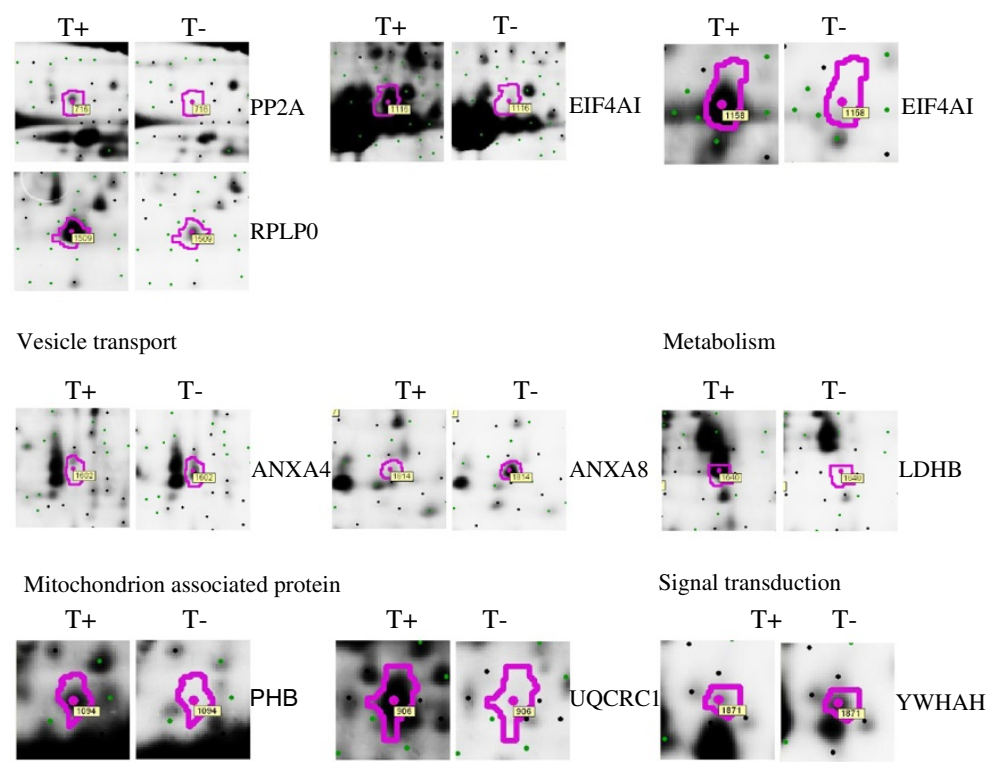

Figure 3 Image of ImageQuant and DeCyder analysis of 35 differentially expressed protein spots in 2D DIGE gels. T+ and T- represent TGEV-infected and mock-infected ST cells, respectively. 

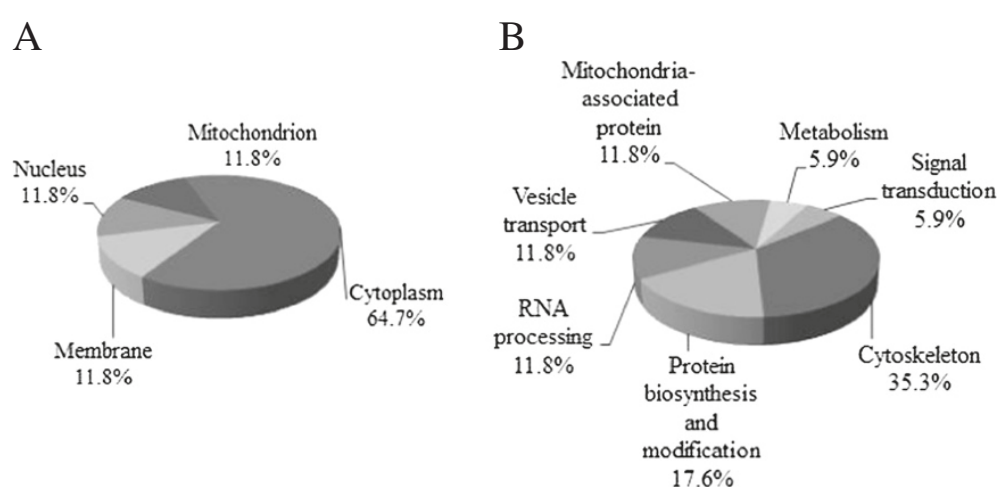

Figure 4 Pie chart representing differentially expressed proteins identified by mass spectrometry following TGEV infected ST cells. Proteins were classified according to their subcellular location (A) and biological function (B).

Additional file 1: Figure S1). According to the protein function and subcellular annotations from the Swiss-Prot and TrEMBL protein database and Gene Ontology Database, the identified cellular proteins were comprised of cellular structure and integrity, RNA processing, protein biosynthesis and modification, vesicle transport, signal transduction, and mitochondrial pathway.

Thirty-three differential protein spots corresponded to 17 proteins, including cytoskeleton-associated proteins (35.3\%), protein biosynthesis and modification proteins (17.6\%), RNA processing proteins (11.8\%), vesicle transport proteins $(11.8 \%)$, mitochondria-associated proteins (5.9\%), signal transduction-associated proteins (5.9\%), and $5.9 \%$ metabolism-associated proteins. These proteins (Figure 3) were mainly located in the cytosol (64.7\%), membrane (11.8\%), nucleus $(11.8 \%)$, and mitochondrion (11.8\%). In addition, some different spots were identified to be products of the same gene, including beta actin, alpha tubulin, vimentin, eukaryotic initiation factor 4A-I, and thiopurine $\mathrm{S}$-methyltransferase. In particular, 7 protein spots (6 up-regulated spots and 1 down-regulated spot) were identified as beta actin, and 8 protein spots (5 up-regulated spots and 3 down-regulated spots) were identified as vimentin.

\section{Analysis of identified proteins at the transcriptional level}

Alterations in expression of a protein may be due to a change in its mRNA level. In order to confirm the results of the proteomics analysis at the mRNA level, the transcriptional alterations in six selected proteins were measured by real-time RT-PCR. Glyceraldehyde-3-phosphate dehydrogenase (GAPDH) gene was used as a control housekeeping gene. The mRNA level of ANXA8 was decreased in TGEV-infected ST cells (Figure 5). The mRNA level of KRT19, TPMT, LDHB, PP2A, UQCRC1 were increased in TGEV-infected ST cells (Figure 5). The trends of change in the mRNA level of ANXA8, TPMT, LDHB, PP2A, and UQCRC1 were consistent with 2D DIGE results. Interestingly, KRT19 had contrary results to with those of 2D DIGE methods. These data provide transcriptional information complementary to those differentiallyexpressed proteins detected by 2D DIGE analysis.

\section{Protein validation by western blot}

To further verify those proteins identified by 2D DIGE and MALDI-TOF/TOF mass spectrometry, Western blot analyses were performed. Three proteins, alpha tubulin, keratin 19, and prohibitin were selected for western blot analysis. Equal amounts of cell lysates from TGEVinfected and mock-infected ST cells at $48 \mathrm{~h}$ p.i. were examined with specific antibodies to alpha tubulin, keratin 19, and prohibitin. The data showed in Figure 6 indicate that alpha tubulin, keratin 19 , and prohibitin were recognized with respective antibodies. From Figure 6, we can see that keratin 19 was down-regulated and alpha tubulin and prohibitin were up-regulated, which was consistent with the 2D DIGE analysis. These data validated the MALDI-TOF/TOF identification of those proteins in TGEV-infected ST cells that differentially expressed.

\section{Discussion}

Proteomics is a novel methodology to detect components of cellular protein interactions as well as host cellular pathophysiological processes that occur during virus infection [11]. Until present investigation, no results have been reported for performing analysis of differential proteome of host cells infected with TGEV. In this study, 2D DIGE coupled with MALDI-TOF/TOF was used to analyze the differential proteome of ST cells infected with TGEV. The 33 differential protein spots were successfully identified as 17 proteins, of which function in diverse biological processes.

Cytoskeletal protein expression was altered in TGEVinfected ST cells. The cytoskeleton filaments are dynamic and divided into three types: microfilaments (actin filament), microtubules, and intermediate filaments 
Table 1 Proteins identified from the differential 2D DIGE analysis after TGEV infection

\begin{tabular}{|c|c|c|c|c|c|c|c|c|c|}
\hline \multirow{2}{*}{$\begin{array}{c}\text { Spot } \\
\text { number }^{\mathrm{a}}\end{array}$} & \multirow[t]{2}{*}{ Protein name (Abbr.) } & \multirow{2}{*}{$\begin{array}{l}\text { Accession } \\
\text { number }\end{array}$} & \multirow{2}{*}{$\begin{array}{l}\text { Molecular } \\
\text { mass }(\mathrm{kDa})\end{array}$} & \multirow[t]{2}{*}{$\mathrm{pl}$} & \multirow{2}{*}{$\begin{array}{l}\text { Peptide } \\
\text { matched }^{c}\end{array}$} & \multirow{2}{*}{$\begin{array}{c}\text { Sequence } \\
\text { coverage (\%) }\end{array}$} & \multirow{2}{*}{$\begin{array}{l}\text { Protein } \\
\text { score }\end{array}$} & \multicolumn{2}{|c|}{ (TGEV/mock) } \\
\hline & & & & & & & & $\begin{array}{c}\text { Average } \\
\text { volume ratio e }\end{array}$ & $p$ value ${ }^{\mathrm{e}}$ \\
\hline \multicolumn{10}{|c|}{ Cytoskeleton proteins } \\
\hline \multicolumn{10}{|c|}{ Microfilament-associated proteins } \\
\hline 1154 & beta actin (ACTB) & gi|45269029 & 44.76 & 5.55 & 3 & 36 & 285 & 3.64 & 0.000035 \\
\hline 1308 & beta actin (ACTB) & gi|45269029 & 44.76 & 5.55 & 3 & 16 & 407 & 4.04 & 0.00013 \\
\hline 1312 & beta actin (ACTB) & gi|45269029 & 44.76 & 5.55 & 3 & 14 & 129 & -2.82 & 0.00076 \\
\hline 1368 & beta actin (ACTB) & gi|45269029 & 44.76 & 5.55 & 1 & 16 & 82 & 4.68 & 0.0097 \\
\hline 1383 & beta actin (ACTB) & gi|45269029 & 44.76 & 5.55 & 5 & 34 & 537 & 3.7 & 0.0019 \\
\hline 1647 & beta actin (ACTB) & gi|150438831 & 44.76 & 5.55 & 3 & 21 & 242 & 7.03 & 0.005 \\
\hline 1675 & alpha tropomyosin (TPM1) & gi|158931149 & 32.69 & 4.71 & 5 & 46 & 544 & -2.82 & 0.0027 \\
\hline 1864 & beta actin (ACTB) & gi|476332 & 26.10 & 5.55 & 3 & 35 & 177 & 2.58 & 0.00023 \\
\hline \multicolumn{10}{|c|}{ Microtubule-associated proteins } \\
\hline 911 & alpha Tubulin (TUBA1B) & gi|116256086 & 50.12 & 4.94 & 4 & 28 & 340 & 9.08 & 0.0029 \\
\hline 964 & beta Tubulin (TUBB) & gi|75045190 & 49.64 & 4.78 & 7 & 31 & 448 & 2.28 & 0.00081 \\
\hline 978 & alpha Tubulin (TUBA1B) & gi|116256086 & 50.12 & 4.94 & 3 & 32 & 338 & 3.38 & 0.000014 \\
\hline \multicolumn{10}{|c|}{ Intermediate filament proteins } \\
\hline 1078 & vimentin (VIM) & gi|335296459 & 53.64 & 5.06 & 6 & 64 & 1020 & -3.26 & 0.0001 \\
\hline 1266 & vimentin (VIM) & gi|335296459 & 53.64 & 5.06 & 6 & 60 & 888 & -4.28 & 0.00013 \\
\hline 1892 & vimentin (VIM) & gi|335296459 & 53.64 & 5.06 & 2 & 35 & 389 & -2.82 & 0.00041 \\
\hline 1947 & vimentin (VIM) & gi|335296459 & 53.64 & 5.05 & 4 & 35 & 582 & 4.84 & 0.000014 \\
\hline 1968 & vimentin (VIM) & gi|21431723 & 30.97 & 4.67 & 4 & 25 & 366 & 3.06 & 0.00036 \\
\hline 1970 & vimentin (VIM) & gi|335296459 & 53.64 & 5.06 & 4 & 35 & 603 & 2.43 & 0.00082 \\
\hline 1907 & keratin 19 (KRT19) & gi|311267276 & 44.19 & 5.05 & 8 & 47 & 682 & -3.99 & 0.000023 \\
\hline 2090 & vimentin (VIM) & gi|21431723 & 30.97 & 4.67 & 2 & 9 & 120 & 5.63 & 0.0095 \\
\hline 2280 & vimentin (VIM) & gi|335296459 & 53.64 & 5.06 & 6 & 34 & 504 & 9.65 & 0.0031 \\
\hline \multicolumn{10}{|c|}{ RNA processing } \\
\hline 1606 & $\begin{array}{c}\text { heterogeneous nuclear } \\
\text { ribonucleoprotein } U \\
\text { (HNRNPU) }\end{array}$ & gi|335296158 & 104.85 & 5.85 & 3 & 7 & 277 & -3.26 & 0.011 \\
\hline 1803 & $\begin{array}{c}\text { thiopurine S-methyltransferase } \\
\text { (TPMT) }\end{array}$ & gi|311259781 & 28.46 & 5.46 & 5 & 41 & 497 & 3.59 & 0.000099 \\
\hline 2023 & $\begin{array}{c}\text { thiopurine S-methyltransferase } \\
\text { (TPMT) }\end{array}$ & gi|311259781 & 28.46 & 5.46 & 5 & 54 & 476 & 6.96 & 0.000008 \\
\hline \multicolumn{10}{|c|}{ Protein biosynthesis and modification } \\
\hline 716 & protein phosphatase 2A (PP2A) & gi|510469 & 65.28 & 5.00 & 2 & 30 & 239 & 2.71 & 0.0051 \\
\hline 1116 & $\begin{array}{c}\text { eukaryotic initiation factor 4A-I } \\
\text { (EIF4A1) }\end{array}$ & gi|154147660 & 46.13 & 5.32 & 7 & 44 & 586 & 3.87 & 0.00052 \\
\hline 1158 & $\begin{array}{c}\text { eukaryotic initiation factor 4A-I } \\
\text { (EIF4A1) }\end{array}$ & gi|154147660 & 46.13 & 5.32 & 5 & 40 & 531 & 3.37 & 0.0011 \\
\hline 1509 & $\begin{array}{l}\text { acidic ribosomal protein P0 } \\
\text { (RPLPO) }\end{array}$ & gi|182705234 & 34.34 & 5.71 & 4 & 50 & 483 & 2.38 & 0.02 \\
\hline \multicolumn{10}{|c|}{ Vesicle transport } \\
\hline 1602 & annexin A8 (ANXA8) & gi|194042330 & 36.71 & 5.20 & 6 & 63 & 752 & -3.31 & 0.0063 \\
\hline 1814 & annexin A4 (ANXA4) & gi|4033507 & 35.81 & 5.71 & 5 & 49 & 510 & -5.96 & 0.000008 \\
\hline
\end{tabular}


Table 1 Proteins identified from the differential 2D DIGE analysis after TGEV infection (Continued)

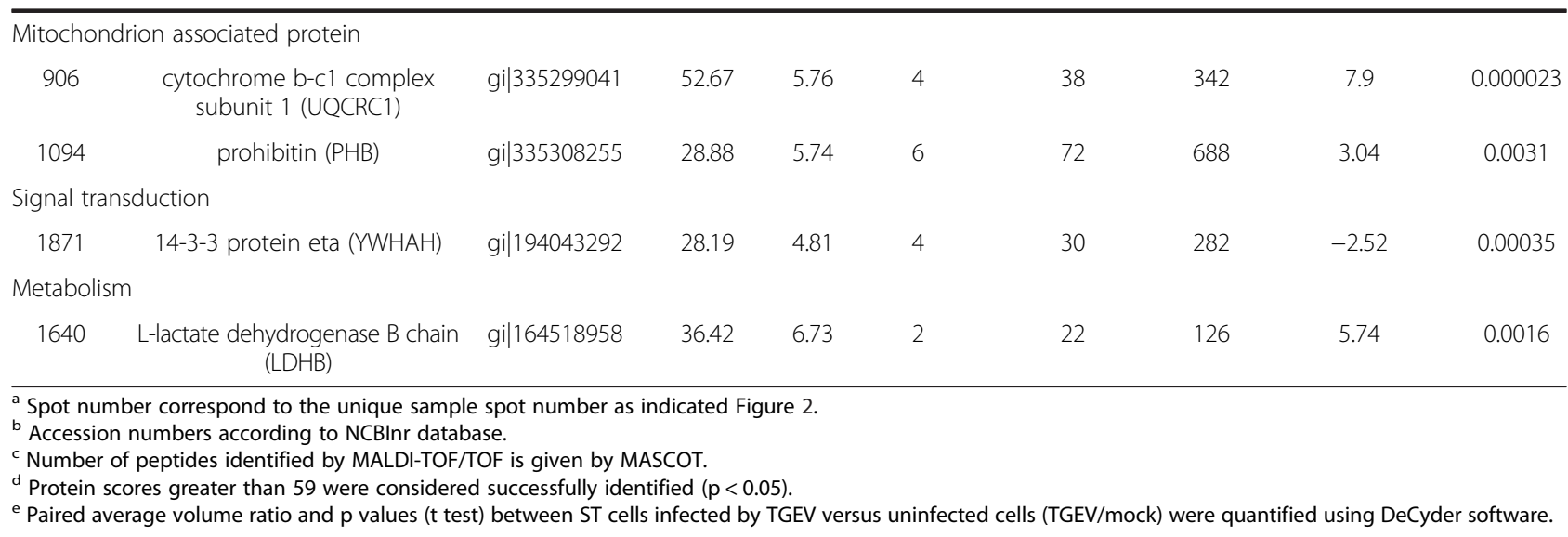

[22]. The intermediate filaments can provide mechanical stability to cells, while actin and microtubule cytoskeletons are responsible for trafficking of numerous endogenous cargos as well as intracellular microorganisms throughout the cells [23]. Many viruses use the cytoskeleton for infection and replication, such as HIV-1 [24]. In present study, differentially expressed microfilament-associated proteins beta actin and alpha tropomyosin, microtubule-associated alpha tubulin and beta tubulin, as well as the intermediate filament-associated vimentin and keratin 19 were identified (Table 1), indicating that TGEV infection and replication involves cellular skeleton.

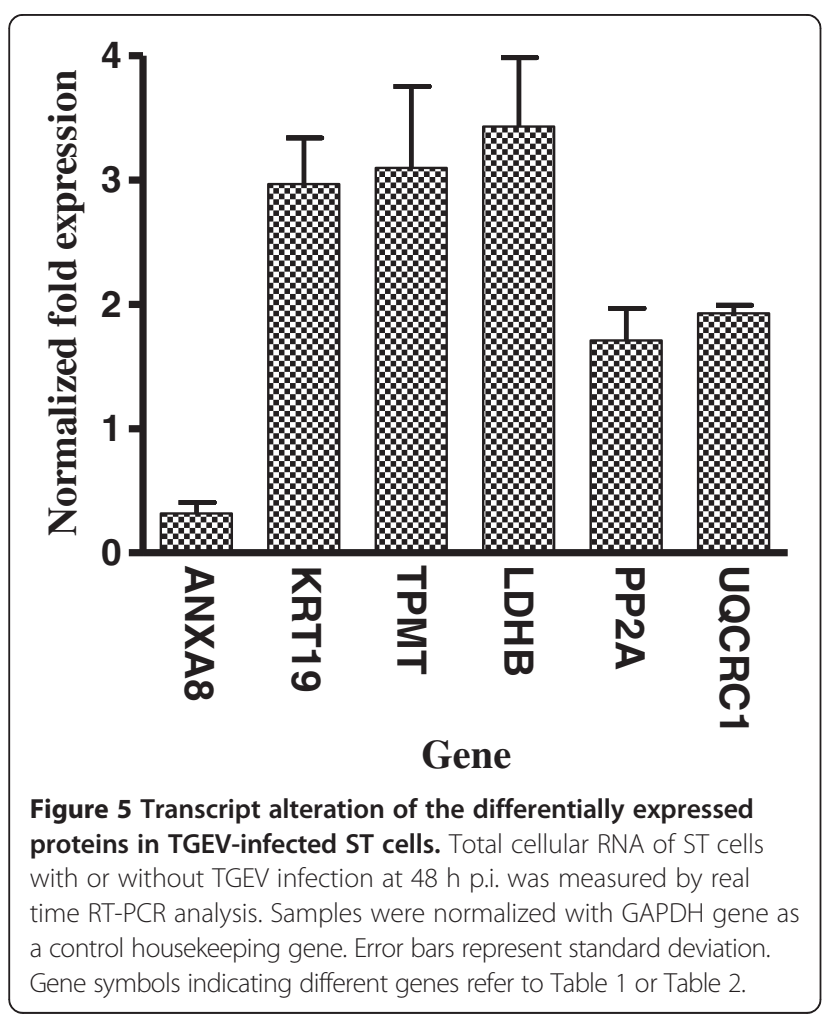

The actin and microtubule cytoskeleton play important roles in the life cycle of viruses [25]. Numerous viral proteins interact with actin-binding proteins or directly with actin [26]. Microtubules and microtubule-associated proteins are known to play important roles in intracellular trafficking of viral components as well as virions in the infected host cell [23]. In this study, the up-regulated microfilament-associated proteins beta actin and microtubule-associated alpha tubulin and beta tubulin were identified, which was believed to facilitate the transport of viral proteins of TGEV from rough endoplasmic reticulum (ER) and Golgi apparatus to the reservoir for viral replication.

Vimentin is a major component of type III intermediate filaments found in many cell lines [27]. This protein serves to maintain cell shape and is involved in attachment, migration and cell signaling [28]. Major changes in the distribution of vimentin are observed when the cell moves and divides [29], but this protein is also redistributed in cells expressing misfolded proteins and during virus infection [30]. Previous studies have shown that intermediate filament protein vimentin was cleaved by human immunodeficiency virus type 1 protease (HIV-1 PR) [31] and that vimentin networks collapsed and was dispersed in IBDV-infected cells [32]. In present study, 8 differential protein spots were identified as vimentin including 5 up-regulated protein spots and 3 down-regulated protein spots. Further study is required to determine whether TGEV papain-like protease 1 ( PL1 $^{\text {pro }}$ ) [33] cleaves vimentin into different isoform or subunit, using a similar strategy as HIV.

Among those differentially expressed host proteins, some are known to participate in viral replication and translation (Table 1). Positive-strand RNA viruses must recruit normal components of host cellular RNA processing or translation machineries for viral RNA synthesis and protein synthesis [34]. Heterogeneous nuclear ribonucleoprotein $\mathrm{U}$ (HNRNPU) is an abundant, strictly 


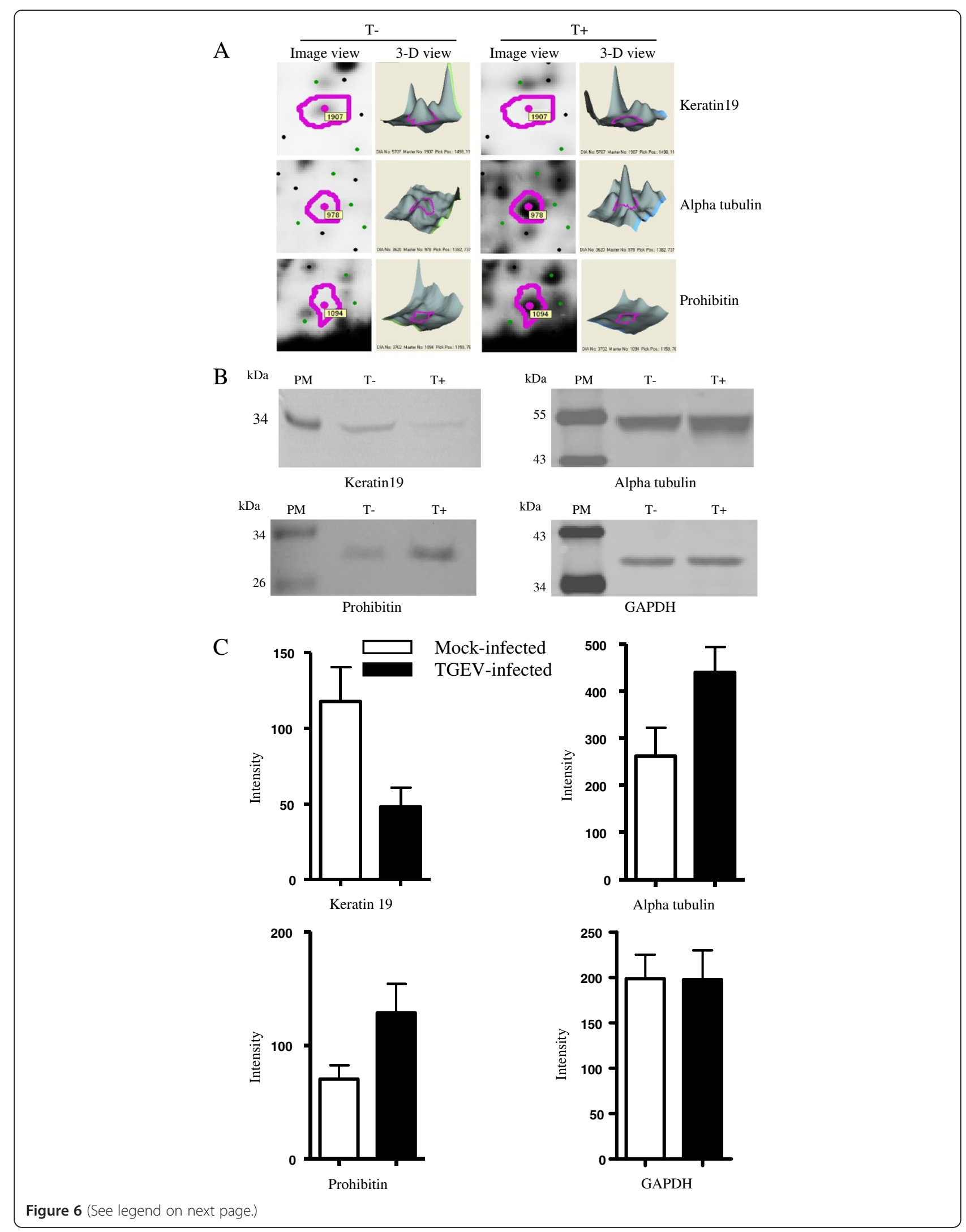


(See figure on previous page.)

Figure 6 Western blot confirmation of representative proteins in TGEV-infected ST cells. Representative image of ImageQuant and DeCyder analysis of keratin19, alpha tubulin, vimentin, and prohibitin in 2D DIGE gels (A). The immunoblot analysis of keratin19, alpha tubulin, vimentin, and prohibitin in TGEV-infected and mock-infected ST cells (B). The averaged densitometric intensity of keratin19, alpha tubulin, vimentin, and prohibitin in immunoblot analysis, with GAPDH as a loading control $(\mathbf{C})$. T + and T- represent TGEV-infected and mock-infected ST cells, respectively. PM, protein marker. Image view and 3-D view obtained from DeCyder.

nuclear phosphoprotein that interacts directly with RNA through a carboxy-terminal RGG sequence [35]. HNRNPU is known to influence pre-mRNA processing, mRNA transportation to cytoplasm, intracellular localization, translation, and turnover of mRNAs [36]. Previous studies have shown that the levels of HIV-1 viral transcripts are dramatically down-regulated in cytoplasm of infected cells by HNRNPU [37]. In this study, the down-regulated HHRNPU was found after TGEV infection, which may facilitate the replication of viruses. Another RNA processing protein, thiopurine S-methyltransferase (TPMT), was found to be more abundant in TGEV-infected cells. TPMT is a cytoplasmic transmethylase present in prokaryotes and eukaryotes, which has a molecular mass of $28 \mathrm{kDa}$ and comprises 245 amino acids [38]. TPMT is a drug-metabolizing enzyme widely expressed in mammalian and non-mammalian cells [39]. Previous works have reported that TPMT plays a role in BVDV virus replication and thiopurines inhibit bovine viral diarrhea virus production in a TPMT-dependent manner [40]. Based on these data, an up-regulation of TPMT in TGEV-infected ST cells suggests that this host protein plays an important role in TGEV biology, making it possible target for future drug development.

Viruses rely on the cellular translation machinery to translate their own proteins, which facilitates the rapid production of viral proteins and renders an inhibitory effect on the production of host proteins, including host anti-viral proteins [41]. Translation factors have been well documented as playing crucial roles in viral RNA and protein synthesis [42]. In herpes simplex virus type 1 (HSV-1) infected HeLa cells, the synthesis of several ribosomal proteins and their assembly into ribosomes continue in spite of a general inhibition of cellular protein synthesis [43]. Acidic ribosomal protein P0 (RPLP0) is located in the active part of the ribosome particle, at which mRNAs, tRNAs and translation factors interact during protein synthesis [44]. The cellular RPLP0 was observed as up-regulated after virus infection, such as pseudorabies virus (PrV) infected bovine kidney cells [45], and Epstein-Barr virus (EBV) infected primary B cells [46]. In this study, the up-regulated 60S RPLP0 was also found after TGEV infection, suggesting the ribosomal protein plays an important role in the translation of TGEV viral proteins.

Viruses may inhibit host protein synthesis by targeting multiple steps in the gene expression process via various pathways, for instance, the vesicular stomatitis virus (VSV) M protein inhibits the initiation of the transcription of host genes [47] and the SARS-CoV spike protein inhibits host cell translation by interaction with eIF3f [48]. In this study, the up-regulated eukaryotic initiation factor 4A-I (EIF4A1) was identified after TGEV infection. The translation initiation proteins observed in TGEV infected ST cells may be a reflection of translation regulation mechanisms exploited by TGEV virus, interfering with cellular protein synthesis and translation initiation of the host cell for beneficial reasons, which need to be further studied.

Protein phosphatase 2A (PP2A) is an evolutionarily conserved enzyme that represents a major portion of serine/ threonine phosphatase activity in cell extracts [49]. PP2A enzymes have been clearly involved in regulation of cell transcription, cell cycle and viral transformation [50]. Upregulation of PP2A scaffold subunit A and subsequent dephosphorylation of Tyr-307 in the catalytic subunit was found, suggesting PP2A activation in Huh7 infected cells [51,52]. Activation of serine-threonine PP2A was found in Huh7 cells upon HSV-1 infection, and PP2A activation paralleled dephosphorylation and inactivation of the downstream mitogen-activated protein (MAP) kinase pathway [53]. In this study, the up-regulation of PP2A was found in TGEV infected ST cells, suggesting PP2A plays an important role in the dephosphorylation of cellular and viral protein during TGEV infection.

Several proteomics analysis about coronavirus had been done including SARS-CoV [54], IBV [55,56], and MHV [57]. By comparing the finding proteins in this study to previous findings, there is no common gene of target related to coronavirus. The findings in TGEV infected ST cell might not reflect the interaction between the virus and pig intestine epithelial cell. It is surprising that the proteome responses observed did not reveal any immune responses related proteins in TGEV-infected ST cells. It may be related to the host cells chosen or the fact that attenuated TGEV strain was used. Identification of cellular proteome in pig intestine epithelial cell or immune cells infected with TGEV need to be further studied.

\section{Conclusions}

In conclusion, a total of 17 altered cellular proteins that differentially expressed in TGEV infection were identified in this study. Most of these proteins were involved in 
transcription and translation processes, vesicle transport, signal transduction, and alteration of the cytoskeleton networks. Western blot analysis of alpha tubulin, keratin 19, and prohibitin validated the MALDI-TOF/TOF identification of the differentially expressed proteins in the TGEV-infected ST cells. The present study provides large scale protein-related information that should be useful for understanding the pathogenesis of TGEV infection.

\section{Materials and methods}

\section{Cell culture, virus infection and sample preparation}

The TGEV strain attenuated H (Accession NO. EU074218) [58] was propagated on a ST cell monolayer. The proteins of TGEV infected ST cells were extracted according to the methods previously described [59]. Briefly, the ST cells were infected with attenuated $\mathrm{H}(\mathrm{H} 167)$ at a multiplication of infection (MOI) of 1 , and the cells were scraped using a cell scraper at $48 \mathrm{~h}$ postinfection (p.i.), and centrifuged at $10,000 \times \mathrm{g}$ for $5 \mathrm{~min}$. After washing three times with icecold phosphate-buffered saline (PBS), the collected cells were lysed with lysis buffer (7 M urea, $2 \mathrm{M}$ thiourea, $4 \%$ [w/v] CHAPS, $65 \mathrm{mM}$ DTT, 0.2\% pharmalyte 4/7 and $1 \mathrm{mM}$ PMSF) containing 1\% nuclease mix in the final concentration and were vertically vibrated until the cells were completely lysed. The supernatant was collected after centrifuging at $12,000 \times \mathrm{g}$ at $4^{\circ} \mathrm{C}$ for $60 \mathrm{~min}$. Samples were treated with a 2D clean-up kit (GE Health Care) and a 2D quant kit (GE Health Care) according to the instructions of the manufacturers. Paralleled mock-infected ST cells were used as control. Three biological replicates of TGEVinfected and mock-infected ST cells were prepared.

\section{D DIGE}

A total of 200 pmol of CyDye DIGE Flours (GE healthcare, Germany) were used to label $50 \mu \mathrm{g}$ of protein samples. To access biological variation, three experimental duplicates were carried out using the samples prepared above. The internal standards (equal amounts of both samples) were labeled with $\mathrm{Cy} 2$. Protein extracts from mock-infected ST cells, used as a reference state, were labeled with Cy5. Protein extracts from TGEV-infected ST cells were labeled with $\mathrm{Cy3}$, representing the test states. IEF was performed using an IPGphor system (GE Healthcare) and commercially available 24-cm long IPG strips (Linear, pH 4-7, GE Healthcare). The settings and conditions for active rehydration of the IPG strips were used as previously described [60]. Briefly, IEF was performed using the following parameters: $30 \mathrm{~V}, 12$ h; $200 \mathrm{~V}, 1$ h; 1,000 V, 1 h; 8,000 V, 2 h; and $8,000 \mathrm{~V}, 65,000 \mathrm{vh}$. The isoelectric-focused proteins in strips were incubated for $15 \mathrm{~min}$ in the equilibration buffer (6 M urea, 30\% glycerol, 2\% SDS, and 0.375 M Tris, $\mathrm{pH} 8.8$ ) containing $1 \%$ DTT, followed by additional equilibration for $15 \mathrm{~min}$ in the equilibration buffer containing $2.5 \%$ iodoacetamide. The second dimension separation was performed using the Ettan Dalt II system (GE healthcare). Gels were poured between low fluorescent glass plates, of which one plate was bind-silane treated. Three parallel gels were run at $12^{\circ} \mathrm{C}$ (running buffer: $25 \mathrm{mM}$ Tris, $192 \mathrm{mM}$ glycine and 1\% SDS). The equilibrated IPG strips were further resolved with $12 \%$ SDS-PAGE gels at $1 \mathrm{~W} /$ gel for $30 \mathrm{~min}$ and then $6 \mathrm{~W} /$ gel until the dye front reached the bottom of the gels.

\section{Image acquisition and analysis of 2D DIGE gels}

Cy2-labeled, Cy3-labeled, and Cy5-labeled protein images were scanned directly between the low fluorescent glass plates using a Typhoon Variable Mode Imager 9400 (GE Healthcare) with the CyDye-specific settings for excitation at $488 \mathrm{~nm}, 532 \mathrm{~nm}$ and $633 \mathrm{~nm}$, and for emission at $520 \mathrm{~nm}, 590 \mathrm{~nm}$ and $680 \mathrm{~nm}$. All gels were scanned with a resolution of $100 \mu \mathrm{m}$ and a standard pixel volume of 60,000-80,000 for all scans. Determination of protein abundance and statistical analysis was performed using the Decyder ${ }^{\mathrm{Ts}}$ software package (version 6.04.11, GE Healthcare). Inter-gel matching performed using the Biological Variation Analysis (BVA) mode. Matching between gels was performed using the in-gel standard from each image pair. A paired $t$ test was used for the methods of statistical analysis. Only protein spots showing significance $(\mathrm{p}<0.05)$ and at least a 2 -fold difference in abundance (ratio of the mean of the normalized spot volume of the TGEV-infected samples versus mock-infected samples) were considered as up-regulated (ratio $>2$ ) or downregulated $($ ratio $<-2$ ).

Table 2 Primers used for real time RT-PCR

\begin{tabular}{|c|c|c|c|c|}
\hline Gene symbol & Forward primers $\left(5^{\prime}-3^{\prime}\right)$ & Reverse primers $\left(5^{\prime}-3^{\prime}\right)$ & Length (bp) & Gene accession no. \\
\hline$\overline{\text { GAPDH }}$ & GGTGAAGGTCGGAGTGAACG & CGTGGGTGGAATCATACTGG & 152 & NM_001206359 \\
\hline ANXA8 & AACCTCCACAGCTACTITGCC & CATCTTGTTGAACTGACCCTTGA & 138 & NM_001243599 \\
\hline KRT19 & AGCGGCAGAATCAGGAGTAC & AGAGGACCTTGGAGGCAGAC & 132 & NM_002276 \\
\hline LDHB & GGAAGATAAACTCAAGGGAGAAATG & CTGCCGTCACCACCACAAT & 128 & NM_001113287 \\
\hline PP2A & GTGGAGAAGTTTGGAAGGAGT & AGCATGTGCTTGGTGGTGAT & 158 & NM_214024 \\
\hline TPMT & CTTCGTCGCCGTTAATCCAG & TCATAAGCCAACACGCACAAG & 99 & NM_001243675 \\
\hline UQCRC1 & GAAGGAAATTGACCAGGAGG & GGGGCAGTAATAACCACC & 169 & XM_003127002 \\
\hline
\end{tabular}




\section{Protein identification by MALDI-TOF-TOF mass spectrometry (MS) and a database search}

For identification of protein spots a preparative gel containing $800 \mu \mathrm{g}$ of protein was run as described above and stained with PhastGel ${ }^{\mathrm{TM}}$ Blue R (GE Healthcare). The protein spots of interest were manually excised from the gels and plated into 96-well microplates. Excised spots were firstly destained twice with $60 \mu \mathrm{l}$ of $50 \mathrm{mM}$ $\mathrm{NH} 4 \mathrm{HCO} 3$ and $50 \%$ acetonitrile $(\mathrm{ACN})$ and then dried twice with $60 \mu \mathrm{l}$ of ACN. Afterwards, the dried pieces of gels were incubated in ice-cold digestion solution (trypsin $12.5 \mathrm{ng} / \mu \mathrm{l}$ and $20 \mathrm{mM} \mathrm{NH} 4 \mathrm{HCO} 3$ ) for $20 \mathrm{~min}$ and then transferred into a $37^{\circ} \mathrm{C}$ incubator for digestion overnight. Finally, peptides in the supernatant were collected after extraction twice with $60 \mu \mathrm{l}$ extract solution $(0.1 \%$ TFA in $50 \% \mathrm{ACN})$. The peptide solution was dried under the protection of $\mathrm{N} 2$, and $0.8 \mu \mathrm{l}$ matrix solution $(5 \mathrm{mg} / \mathrm{ml} \alpha-$ cyano-4-hydroxy-cinnamic acid diluted in 0.1\%TFA, 50\% $\mathrm{ACN}$ ) was pipetted to dissolve it. Then the mixture was spotted on a MALDI target plate (Applied Biosystems). MS analysis of peptides was performed on an AB SCIEX 5800 MALDI-TOF/TOF. The UV laser was operated at a $400 \mathrm{~Hz}$ repetition rate with wavelength of $355 \mathrm{~nm}$. The accelerated voltage was operated at $20 \mathrm{kV}$ and mass resolution was maximized at 1,600 Da. Myoglobin digested with trypsin was used to calibrate the mass instrument with an internal calibration mode. All acquired spectra from samples were processed using TOF/TOF Explore ${ }^{\mathrm{TM}}$ Software in a default mode. The data were searched by GPS Explorer (V3.6) with the search engine MASCOT (2.1). The following parameters were used in the search: National Center for Biotechnology information nonredundant (NCBInr) database (release date, July, 2011), Sus scrofa, protein molecular mass ranged from 700 to 3,600 Da, trypsin digest with one missing cleavage, peptide tolerance of $100 \mathrm{ppm}, \mathrm{MS} / \mathrm{MS}$ tolerance of $0.8 \mathrm{Da}$ and possible oxidation of methionine. Known contaminant ions (tryptic autodigest peptides) were excluded. A total of 41,373 sequences and 16,019,616 residues in the database were actually searched. All identified proteins had a protein score greater than 59, corresponding to a statistically significant $(\mathrm{p}<0.05)$ confident identification. Besides protein score, at least one ion score with $\mathrm{p}<0.05$ was recommended to increase the reliability of identifications.

\section{Western blot}

Samples of TGEV-infected and mock-infected ST cells were lysed at $48 \mathrm{~h}$ p.i., and the protein concentration was determined. Equivalent amounts of cell lysates $(60 \mu \mathrm{g})$ were subjected to $12 \%$ SDS-PAGE gels and then transferred to $0.22 \mu \mathrm{m}$ nitrocellulose membranes (Hybond-C extra, Amersham Biosciences). After blotting, the membranes were incubated with mouse monoclonal antibody (mAb) to alpha tubulin (1:1000, Abcam), mAb to prohibitin (1:500, II-14-10, Santa Cruz), and rabbit polyclonal antibody to keratin19 (1:500, Bioss) at $37^{\circ} \mathrm{C}$ for $60 \mathrm{~min}$. After washing three times with PBST, the membranes were inoculated with horseradish peroxidase (HRP) conjugated goat anti-mouse IgG (Kirkegaard \& Perry Laboratories, Inc.) or goat anti-rabbit IgG (Kirkegaard \& Perry Laboratories, Inc.) at $37^{\circ} \mathrm{C}$ for $60 \mathrm{~min}$ and visualized using 3,3',5,5' -tetramethylbenzidine-stabilized substrate (TMB, Promega).

\section{Real time RT-PCR}

Total RNA was extracted from the ST cells, which were infected with TGEV for $48 \mathrm{~h}$, using the EZ-10 Spin Column RNA Purification Kit (Qiagen) according to the manufacturer's protocol. cDNA synthesis was performed with $1 \mu \mathrm{g}$ of total cellular RNA using a RevertAid ${ }^{\mathrm{Tm}}$ first strand cDNA synthesis kit (Fermentas), according to manufacturer's protocol. The specific primers for amplifying various target genes for differentially expressed proteins were designed according to the available gene sequences deposited in GenBank using Lasergene sequence analysis software (DNAStar, Inc., Madison, WI, USA) (Table 2). Real time RT-PCR was performed using a LightCycler 480 II (Roche) in a total volume of $20 \mu \mathrm{L}$ containing $10 \mathrm{ng}$ of cDNA template, $1 \times \mathrm{SYBR}^{\oplus}$ Premix Ex Taq ${ }^{\mathrm{TM}}$ II (Perfect Real Time, TaKaRa), and a $0.4 \mu \mathrm{M}$ concentration of each primer. After initial denaturation at $95^{\circ} \mathrm{C}$ for $2 \mathrm{~min}$, the amplification was performed for 40 cycles, each consisting of denaturation at $95^{\circ} \mathrm{C}$ for $5 \mathrm{~s}$ and primer annealing at $55^{\circ} \mathrm{C}$ for 15 s. Melting curves were obtained, and quantitative analysis of the data was performed in a relative quantification $\left(2^{-\Delta \Delta C T}\right)$ study model. Parallel mock-infected ST cells were used as control (relative expression =1) and GAPDH as an internal reference gene.

\section{Additional files}

Additional file 1: Figure S1. MS and MS/MS spectra of the identiifed protein spots.

Additional file 2: Table S1. Cell proteins identified from the differential 2D DIGE analysis after TGEV infection.

\begin{abstract}
Abbreviations
2D DIGE: Two-dimensional difference gel electrophoresis; ACN: Acetonitrile; CHAPS: 3-[(3-cholamidopropyl) dimethyl-ammonio]-1-propanesulfonate; DTT: Dithiothreitol; GAPDH: Glyceraldehyde-3-phosphate dehydrogenase; TGEV: Transmissible gastroenteritis coronavirus; IEF: Isoelectric focusing; IPG: Immobilized pH gradient; MALDI-TOF-TOF/MS: Matrix-assisted laser desorption/ionization time-of-flight tandem mass spectrometry; RT-PCR: Reverse transcriptase-polymerase chain reaction; PMF: Peptide mass fingerprinting; SDS-PAGE: Sodium dodecyl sulfate polyacrylamide gel electrophoresis.
\end{abstract}

Competing interests

The authors declare that they have no competing interests. 


\section{Authors' contributions}

LF designed the study. LF and XZ were responsible for data analysis and interpretation and drafted the manuscript; HS, JC, and DS carried out the 2D DIGE gel analysis and excised the protein spots; HL and ZW were responsible for mass spectrometry analysis and manuscript editing. All authors read and approved the final manuscript.

\section{Acknowledgements}

This work was supported by the National Natural Science Foundation of China (Grant No.31172350), Heilongjiang Provincial Natural Science Foundation (Grant No.JC201118) and Research Team Program on Scientific and Technological Innovation in Heilongjiang Provincial University (Grant No.2011TD001). We thank Mr. Wang Shao (Institute of Animal Husbandry and Veterinary Science, Fujian Academy of Agricultural Science, China) for the donation of mAb to $\mathrm{N}$ protein of TGEV. We thank the studies about proteomics analysis of other coronavirus because these studies about coronavirus are very close to this work

\section{Author details}

${ }^{1}$ Division of Swine Infectious Diseases, State Key Laboratory of Veterinary Biotechnology, Harbin Veterinary Research Institute, Chinese Academy of Agricultural Sciences, No. 427 Maduan Street, Nangang District, Harbin 150001, China. ${ }^{2}$ Chinese Institute of Veterinary Drug Control, Beijing 100081 China.

Received: 6 March 2013 Accepted: 23 June 2013

Published: 16 July 2013

\section{References}

1. Masters PS: The molecular biology of coronaviruses. Adv Virus Res 2006, 66:193-292

2. Sestak K, Lanza I, Park SK, Weilnau PA, Saif LJ: Contribution of passive immunity to porcine respiratory coronavirus to protection against transmissible gastroenteritis virus challenge exposure in suckling pigs. Am J Vet Res 1996, 57:664-671.

3. Penzes Z, Gonzalez JM, Calvo E, Izeta A, Smerdou C, Mendez A, Sanchez CM, Sola I, Almazan F, Enjuanes L: Complete genome sequence of transmissible gastroenteritis coronavirus PUR46-MAD clone and evolution of the purdue virus cluster. Virus Genes 2001, 23:105-118.

4. Schwegmann-Wessels C, Zimmer G, Laude H, Enjuanes L, Herrler G: Binding of transmissible gastroenteritis coronavirus to cell surface sialoglycoproteins. J Virol 2002, 76:6037-6043.

5. Escors D, Camafeita E, Ortego J, Laude H, Enjuanes L: Organization of two transmissible gastroenteritis coronavirus membrane protein topologies within the virion and core. J Virol 2001, 75:12228-12240.

6. Escors D, Ortego J, Laude H, Enjuanes L: The membrane M protein carboxy terminus binds to transmissible gastroenteritis coronavirus core and contributes to core stability. J Virol 2001, 75:1312-1324.

7. Godet M, L'Haridon R, Vautherot JF, Laude H: TGEV corona virus ORF4 encodes a membrane protein that is incorporated into virions. Virology 1992, 188:666-675.

8. Calvo E, Escors D, Lopez JA, Gonzalez JM, Alvarez A, Arza E, Enjuanes L: Phosphorylation and subcellular localization of transmissible gastroenteritis virus nucleocapsid protein in infected cells. J Gen Virol 2005, 86:2255-2267.

9. Kapke PA, Brian DA: Sequence analysis of the porcine transmissible gastroenteritis coronavirus nucleocapsid protein gene. Virology 1986, 151:41-49.

10. Wurm T, Chen H, Hodgson T, Britton P, Brooks G, Hiscox JA: Localization to the nucleolus is a common feature of coronavirus nucleoproteins, and the protein may disrupt host cell division. J Virol 2001, 75:9345-9356.

11. Maxwell KL, Frappier L: Viral proteomics. Microbiol Mol Biol Rev 2007. 71:398-411.

12. Go EP, Wikoff WR, Shen Z, O'Maille G, Morita H, Conrads TP, Nordstrom A, Trauger SA, Uritboonthai W, Lucas DA, Chan KC, Veenstra TD, Lewicki H, Oldstone MB, Schneemann A, Siuzdak G: Mass spectrometry reveals specific and global molecular transformations during viral infection. J Proteome Res 2006, 5:2405-2416.

13. Unlu M, Morgan ME, Minden JS: Difference gel electrophoresis: a single gel method for detecting changes in protein extracts. Electrophoresis 1997, 18:2071-2077.
14. Patton WF: Detection technologies in proteome analysis. J Chromatogr B Analyt Technol Biomed Life Sci 2002, 771:3-31.

15. Vester D, Rapp E, Gade D, Genzel Y, Reichl U: Quantitative analysis of cellular proteome alterations in human influenza a virus-infected mammalian cell lines. Proteomics 2009, 9:3316-3327.

16. Coiras M, Camafeita E, Urena T, Lopez JA, Caballero F, Fernandez B, Lopez-Huertas MR, Perez-Olmeda M, Alcami J: Modifications in the human $T$ cell proteome induced by intracellular HIV-1 tat protein expression. Proteomics 2006, 6:63-73.

17. Huang Q, Wang L, Bai S, Lin W, Chen W, Lin J, Lin X: Global proteome analysis of hepatitis B virus expressing human hepatoblastoma cell line HepG2. J Med Virol 2009, 81:1539-1550.

18. De Re V, Simula MP, Cannizzaro R, Sansonno D, Canzonieri V, Gloghini A Carbone A, Colombatti A, Marin MD, De Zorzi M, Toffoli G: HCV inhibits antigen processing and presentation and induces oxidative stress response in gastric mucosa. Proteomics Clin Appl 2008, 2:1290-1299.

19. Cao JY, Mansouri S, Frappier $L$ : Changes in the nasopharyngeal carcinoma nuclear proteome induced by the EBNA1 protein of epstein-barr virus reveal potential roles for EBNA1 in metastasis and oxidative stress responses. J Virol 2012, 86:382-394.

20. Patramool S, Surasombatpattana P, Luplertlop N, Seveno M, Choumet V, Thomas F, Misse D: Proteomic analysis of an aedes albopictus cell line infected with dengue serotypes 1 and 3 viruses. Parasit Vectors 2011, 4:138-145.

21. Yang Y, An T, Gong D, Li D, Peng J, Leng C, Yuan Z, Tong G, Tian Z, Zhang D: Identification of porcine serum proteins modified in response to HP-PRRSV HuN4 infection by two-dimensional differential gel electrophoresis. Vet Microbiol 2012, 158:237-246.

22. Naghavi MH, Goff SP: Retroviral proteins that interact with the host cell cytoskeleton. Curr Opin Immunol 2007, 19:402-407.

23. Greber UF, Way M: A superhighway to virus infection. Cell 2006, 124:741-754

24. Soll DR: Researchers in cell motility and the cytoskeleton can play major roles in understanding AIDS. Cell Motil Cytoskeleton 1997, 37:91-97.

25. Radtke K, Dohner K, Sodeik B: Viral interactions with the cytoskeleton: a hitchhiker's guide to the cell. Cell Microbiol 2006, 8:387-400.

26. Cudmore S, Reckmann I, Way M: Viral manipulations of the actin cytoskeleton. Trends Microbiol 1997, 5:142-148.

27. Franke WW, Schmid E, Winter S, Osborn M, Weber K: Widespread occurrence of intermediate-sized filaments of the vimentin-type in cultured cells from diverse vertebrates. Exp Cell Res 1979, 123:25-46.

28. Ivaska J, Pallari HM, Nevo J, Eriksson JE: Novel functions of vimentin in cell adhesion, migration, and signaling. Exp Cell Res 2007, 313:2050-2062.

29. Yoon M, Moir RD, Prahlad V, Goldman RD: Motile properties of vimentin intermediate filament networks in living cells. J Cell Biol 1998, 143:147-157.

30. Stefanovic S, Windsor M, Nagata Kl, Inagaki M, Wileman T: Vimentin rearrangement during African swine fever virus infection involves retrograde transport along microtubules and phosphorylation of vimentin by calcium calmodulin kinase II. J Virol 2005, 79:11766-11775.

31. Shoeman RL, Honer B, Stoller TJ, Kesselmeier C, Miedel MC, Traub P, Graves MC Human immunodeficiency virus type 1 protease cleaves the intermediate filament proteins vimentin, desmin, and glial fibrillary acidic protein. Proc Natl Acad Sci USA 1990, 87:6336-6340.

32. Zheng X, Hong L, Shi L, Guo J, Sun Z, Zhou J: Proteomics analysis of host cells infected with infectious bursal disease virus. Mol Cell Proteomics 2008, 7:612-625.

33. Wojdyla JA, Manolaridis I, van Kasteren PB, Kikkert M, Snijder EJ, Gorbalenya AE, Tucker PA: Papain-like protease 1 from transmissible gastroenteritis virus: crystal structure and enzymatic activity toward viral and cellular substrates. J Virol 2010, 84:10063-10073.

34. Li HP, Huang P, Park S, Lai MM: Polypyrimidine tract-binding protein binds to the leader RNA of mouse hepatitis virus and serves as a regulator of viral transcription. J Virol 1999, 73:772-777.

35. Pinol-Roma S, Dreyfuss G: hnRNP proteins: localization and transport between the nucleus and the cytoplasm. Trends Cell Biol 1993, 3:151-155

36. Dreyfuss G, Kim VN, Kataoka N: Messenger-RNA-binding proteins and the messages they carry. Nat Rev Mol Cell Biol 2002, 3:195-205.

37. Valente ST, Goff SP: Inhibition of HIV-1 gene expression by a fragment of hnRNP U. Mol Cell 2006, 23:597-605.

38. Krynetski E, Evans WE: Drug methylation in cancer therapy: lessons from the TPMT polymorphism. Oncogene 2003, 22:7403-7413. 
39. Woodson LC, Weinshilboum RM: Human kidney thiopurine methyltransferase. purification and biochemical properties. Biochem Pharmacol 1983, 32:819-826.

40. Hoover S, Striker R: Thiopurines inhibit bovine viral diarrhea virus production in a thiopurine methyltransferase-dependent manner. J Gen Virol 2008, 89:1000-1009.

41. Silverman RH, Williams BR: Translational control perks up. Nature 1999, 397:208-211.

42. Kushner DB, Lindenbach BD, Grdzelishvili VZ, Noueiry AO, Paul SM, Ahlquist P: Systematic, genome-wide identification of host genes affecting replication of a positive-strand RNA virus. Proc Natl Acad Sci USA 2003, 100:15764-15769.

43. Greco A, Laurent AM, Madjar JJ: Repression of beta-actin synthesis and persistence of ribosomal protein synthesis after infection of HeLa cells by herpes simplex virus type 1 infection are under translational control. Mol Gen Genet 1997, 256:320-327.

44. Wool IG, Chan YL, Gluck A, Suzuki K: The primary structure of rat ribosomal proteins $\mathrm{P} 0, \mathrm{P} 1$, and $\mathrm{P} 2$ and a proposal for a uniform nomenclature for mammalian and yeast ribosomal proteins. Biochimie 1991, 73:861-870.

45. Skiba M, Mettenleiter TC, Karger A: Quantitative whole-cell proteome analysis of pseudorabies virus-infected cells. J Virol 2008, 82:9689-9699.

46. Schlee M, Krug T, Gires O, Zeidler R, Hammerschmidt W, Mailhammer R, Laux G, Sauer G, Lovric J, Bornkamm GW: Identification of epstein-barr virus (EBV) nuclear antigen 2 (EBNA2) target proteins by proteome analysis: activation of EBNA2 in conditionally immortalized $B$ cells reflects early events after infection of primary B cells by EBV. J Virol 2004, 78:3941-3952

47. Ahmed M, McKenzie MO, Puckett S, Hojnacki M, Poliquin L, Lyles DS: Ability of the matrix protein of vesicular stomatitis virus to suppress beta interferon gene expression is genetically correlated with the inhibition of host RNA and protein synthesis. J Virol 2003, 77:4646-4657.

48. Xiao H, Xu LH, Yamada Y, Liu DX: Coronavirus spike protein inhibits host cell translation by interaction with elF3f. PLoS One 2008, 3:1494-1499.

49. Labib K, Nurse P: Cell cycle: bring on the phosphatases. Curr Biol 1993, 3:164-166.

50. Garcia A, Cayla X, Sontag E: Protein phosphatase 2A: a definite player in viral and parasitic regulation. Microbes Infect 2000, 2:401-407.

51. Chen J, Martin BL, Brautigan DL: Regulation of protein serine-threonine phosphatase type-2A by tyrosine phosphorylation. Science 1992, 57:1261-1264

52. Chen J, Parsons S, Brautigan DL: Tyrosine phosphorylation of protein phosphatase $2 \mathrm{~A}$ in response to growth stimulation and v-src transformation of fibroblasts. J Biol Chem 1994, 269:7957-7962.

53. Santamaria E, Mora MI, Potel C, Fernandez-Irigoyen J, Carro-Roldan E, Hernandez-Alcoceba R, Prieto J, Epstein AL, Corrales FJ: Identification of replication-competent HSV-1 Cgal + strain signaling targets in human hepatoma cells by functional organelle proteomics. Mol Cell Proteomics 2009, 8:805-815.

54. Jiang X, Tang L, Dai J, Zhou H, Li S, Xia Q, Wu J, Zeng R: Quantitative analysis of severe acute respiratory syndrome (SARS)-associated coronavirus-infected cells using proteomic approaches. Mol Cell Proteomics 2005, 4:902-913

55. Emmott E, Rodgers MA, Macdonald A, McCrory S, Ajuh P, Hiscox JA: Quantitative proteomics using stable isotope labeling with amino acids in cell culture (SILAC) reveals changes in the cytoplasmic, nuclear and nucleolar proteomes in vero cells infected with the coronavirus infectious bronchitis virus. Mol Cell Proteomics 2010, 9:1920-1936.

56. Cao Z, Han Z, Shao Y, Liu X, Sun J, Yu D, Kong X, Liu S: Proteomics analysis of differentially expressed proteins in chicken trachea and kidney after infection with the highly virulent and attenuated coronavirus infectious bronchitis virus in vivo. Proteome Science 2012, 10:24-43.

57. Vogels MW, van Balkom BW, Kaloyanova DV, Batenburg JJ, Heck AJ, Helms JB, Rottier PJ, de Haan CA: Identification of host factors involved in coronavirus replication by quantitative proteomics analysis. Proteomics 2011, 11:64-80.

58. Wang C, Chen J, Shi H, Qiu H, Xue F, Liu C, Zhu Y, Liu S, Almazan F, Enjuanes L, Feng L: Molecular characterization of a Chinese vaccine strain of transmissible gastroenteritis virus: mutations that may contribute to attenuation. Virus Genes 2010, 40:403-409.
59. Zhang $X$, Zhou J, Wu $Y$, Zheng $X, M a ~ G$, Wang Z, Jin $Y$, He J, Yan $Y$ : Differential proteome analysis of host cells infected with porcine circovirus type 2. J Proteome Res 2009, 8:5111-5119.

60. Cao Z, Han Z, Shao Y, Geng H, Kong X, Liu S: Proteomic analysis of chicken embryonic trachea and kidney tissues after infection in ovo by avian infectious bronchitis coronavirus. Proteome Sci 2011, 9:11-18.

doi:10.1186/1477-5956-11-31

Cite this article as: Zhang et al:: Identification of cellular proteome using two-dimensional difference gel electrophoresis in ST cells infected with transmissible gastroenteritis coronavirus. Proteome Science 2013 11:31.

\section{Submit your next manuscript to BioMed Central and take full advantage of:}

- Convenient online submission

- Thorough peer review

- No space constraints or color figure charges

- Immediate publication on acceptance

- Inclusion in PubMed, CAS, Scopus and Google Scholar

- Research which is freely available for redistribution

Submit your manuscript at www.biomedcentral.com/submit
C) Biomed Central 